\title{
LA MORAL DE LA VIDA COTIDIANA Y SU RELACIÓN CON LAS PREGUNTAS ÉTICAS
}

\author{
THE ROLE AND CHALLENGES OF ETHICS IN DAILY LIFE
}

Myriam Falla De Güich*

\section{Resumen}

Este artículo intenta reflexionar sobre la moral en la vida cotidiana y la urgente toma de decisiones a las que el individuo humano está sujeto constantemente. El sujeto moral se enfrenta a una variedad de dilemas constantemente, por eso es preciso pensar de modo ético las salidas ante los casos de mayor atención.

Palabras clave: moral, ética

\section{Abstract}

This article tries to reflect on morality in everyday life and the urgent decision making to which the human individual is constantly subject. The moral subject is constantly faced with a variety of dilemmas, which is why it is necessary to think in an ethical way about the exits in cases of greater attention.

Keywords: moral, éthics

Licenciada en Filosofía por la PUCP. Doctora en Filosofía por la Pontificia Universidad Católica Argentina. 
Nuestra época actual, plagada de idas y venidas, en medio de los quehaceres de la vida cotidiana, hace que nos introduzcamos en un mundo donde no hay un lugar para preguntarnos si lo que hacemos está bien o mal, si responden a un parámetro ético o no, si nos perjudicamos a nosotros mismos o al prójimo, si nos conviene un determinado comportamiento o no y si aceptamos impunemente lo que ocurre a nuestro alrededor.

La vida cotidiana no nos deja pensar incluso, si las pequeñas cosas que hemos cometido adquieren un cariz de moralidad, amoralidad o inmoralidad. Por eso, se hace necesaria la pregunta en determinados momentos de nuestras vidas que nos permitan esta opción. La educación juega un papel preponderante en este asunto, dado que lo que asimilamos en el hogar y en la escuela constituirá el punto a partir del cual podamos cuestionar nuestros actos.

La moral individual no opera sólo en el individuo dejando al margen el aspecto social, sino que ambos están concatenados y se retroalimentan mutuamente. Dicho en otros términos, si la moral individual compromete lo social no se puede pensar en un acto individual que no trascienda a la esfera social y tenga un efecto sobre ella.

Aristóteles (2002) desarrolló toda una teoría de la virtud que se adquiere por hábito hasta llegar al "justo medio de eminencia". Este justo medio no se calcula matemáticamente sino que es fruto de la phronesis o prudencia del hombre que lo pone en práctica. Así por ejemplo, un individuo decide no renunciar a su empleo aun sabiendo que sus compañeros lo han hecho por mostrar ciertos desacuerdos con el sindicato de trabajadores. Muchos lo acusarán de traidor, pero podemos entender que incluso en este caso se aplicó la phronesis, dado que del sueldo que recibe depende la manutención de su familia, siendo para él difícil ubicarse en otro puesto de trabajo. El justo medio entre dos extremos que pecan por exceso o defecto es lo que lo llevó a esa decisión.

No se trata de que el fin justifique los medios, sino de una medida cautelosa que no compromete el bienestar de quienes dependen de él.

Es una cuestión difícil de calificar teniendo en cuenta las futuras y posibles consecuencias que esto le pueda traer, pero en la vida cotidiana es lo que entendió por una decisión moralmente correcta según el momento que le tocó vivir. Aquí vemos claramente cómo una decisión individual compromete el ámbito social, ya sea para bien o para mal. 
Quien se planteó una prueba sobre la veracidad moral de nuestras acciones fue, precisamente, Immanuel Kant (1981), quien con su imperativo categórico jugó con la posibilidad de que la acción cometida por el individuo pase la prueba de convertirse en legislación universal, es decir, que sea consensualmente aceptada, de lo contrario el acto no puede calificarse de moral. Pero es difícil que el individuo cotidiano esté pensando en el imperativo categórico a la hora de actuar o de evaluar su acto ya que la naturaleza académica del mismo lo aleja de él, e incluso habría que tomar en cuenta la moral aceptada por cada comunidad o etnia, siendo incluso permisible o no los actos en cuestión. Hablar de una moral universal no es fácil, teniendo en cuenta que universalmente nos encontramos con culturas que no siguen los mismos parámetros ${ }^{1}$. La solución a este impase es que los sujetos se atengan a la moral religiosa que practican o la que es comúnmente aceptada en su comunidad o a preceptos jurídicos que la respaldan.

Hoy en día es difícil plantear dilemas con soluciones, teniéndose que acudir a principios que guíen y avalen el comportamiento humano. Por ejemplo, qué hacer si tenemos un paciente gravemente enfermo con el que todavía se puede probar un tratamiento experimental y del cual, al no haber resultados estadísticos seguros pueda acarrearle prontamente la muerte ${ }^{2}$. En estos casos no queda más que el guiar humano acontezca a través de principios que alumbren la acción de quien debe tomar la decisión. Una salida al respecto es el respaldo del "principio del doble efecto" ${ }^{3}$ tantas veces cuestionado por considerársele obsoleto. Todas estas cuestiones que aparecen en la vida cotidiana y en ocasiones específicas, hacen que el individuo se pregunte sobre la bondad de su actuar. Aristóteles ${ }^{4}$ dice que para estos acontecimientos no hay más que obrar virtuosamente. ¿Qué entiende Aristóteles por virtud y cómo se logra? La virtud se adquiere por hábito y no es más que obrar según la recta razón del hombre prudente y juicioso. Esta prudencia o phronesis no es más que el justo medio de eminencia que se opone ante dos extremos, el exceso y el defecto, como lo señalamos anteriormente. Así, por ejemplo, la valentía es el justo medio entre la temeridad (exceso) y la cobardía (defecto). El filósofo de Estagirita enumera una serie de virtudes

Esta figura aparece cuando diferentes culturas arraigadas en la fuerza de la costumbre irrumpen con soluciones que pueden llegar hasta el hecho de hacer justicia por uno mismo o por el propio pueblo. Esto nos recuerda cuando en la localidad de Ilave, Puno, los lugareños mataron a su alcalde para hacer justicia propia, ya que éste estaba cometiendo irregularidades en la región.

2 Esto tiene que ver con los tratamientos experimentales que se dan a los pacientes cuando no hay solución terapéutica viable. La intención no es acarrearle prontamente la muerte sino buscar alargarle la vida a través de terapias que si bien no son comercializadas aún, pueden jugar un papel importante en la evolución y detenimiento de la enfermedad.

3 Principio ético que nace con la moral católica y que se enuncia así: El mal que se tolera debe ser proporcionalmente grave al bien que se persigue. Este principio fue reemplazado posteriormente por el Principio de Totalidad, y luego, por un corolario, el Principio del mal menor. El Principio del doble efecto conserva a nuestro parecer, toda su riqueza, apareciendo con un enunciado que pone condiciones al sujeto que lo va a emplear en la solución de un caso particular. El efecto malo solo debe ser tolerado frente a una situación en la que "no hay salida".

4 Aristóteles, ob.cit 
a modo ejemplificador de cómo debe comportarse el individuo frente a una situación particular. Con esto no hace más que proponer principios que puedan servir de guía para el correcto actuar humano.

Sin embargo, estas proposiciones aristotélicas, así como el consenso de la moral kantiana, se convierten en morales que deben tomarse con cuidado. En primer lugar, si bien es cierto que ambas morales son hijas de su tiempo y pretenden ser universales, a simple vista no lo son. Quizá la moral kantiana, si la respaldamos en el concepto paulino de Ley Moral Natural (Rom, 2, 1216) pueda acercarse a una concordia universal, pero para juzgar la bondad de los actos humanos tenemos que presuponer que todas las culturas aceptan los mismos principios para juzgar lo bueno de lo malo, y en la realidad pluricultural sabemos que no es así. El ser humano vive en una cultura que le es propia con sus propios criterios evaluadores.

¿Cómo hablar entonces de una moral de la vida cotidiana en un rango universal?

La tarea no es fácil, del mismo modo cuando nos referimos a los derechos humanos. El concepto de "derechos humanos" es hijo de nuestro tiempo, y para poder hablar de ellos con propiedad, hay que presuponer que siempre han existido. De lo que siempre se habló a lo largo de la historia de la filosofía es de "derecho natural" vinculado a la moral, pero los derechos humanos reclamados a partir de la Segunda Guerra Mundial son convocados, hoy por hoy.

Si aceptamos la teoría de que siempre existió el derecho natural, entonces, respaldados en esta doctrina es posible hablar de derechos humanos a lo largo de la historia, aunque estos se hayan infringido infinidad de veces. Por eso, en el ámbito de la moralidad natural se abre la puerta jurídica de las acciones para todos los tiempos. Sólo así podemos respaldarnos en una moral y un derecho universal.

La ética estricta de Kant no nos deja lugar para un justo medio de eminencia, como lo proponía Aristóteles. La inamovilidad de sus requerimientos nos dejan con un al "sí, sí y al no, no". Hoy, con la infinidad de cuestiones morales que nos plantean la ética y la bioética, no podemos resolver dilemas morales y casos de perplejidad con la prueba del imperativo, sino, como se dijo anteriormente, tenemos que recurrir a principios que nos permitan una salida digna.

A pesar de la claridad de sus enunciados, los individuos se preguntan siempre si su actuar fue correcto, porque la situación que los envuelve los 
invita a ello. En el caso citado más arriba, la solución que se plantea es proporcionar ayuda médica al paciente como último recurso de tratamiento. Pero en la vida cotidiana, y con los sentimientos muchas veces encontrados que provocan situaciones de este tipo, no siempre es fácil la respuesta adecuada. Los familiares de los pacientes- continuando con esta casuísticase ven obligados a recurrir a comités médicos (si es que la institución hospitalaria los tiene) buscando una salida. Otros recurrirán a la interioridad de su conciencia para resolver el dilema.

Doble efecto, mal menor o derecho prevalente ${ }^{5}$, son los principios que van a establecer un puente y una salida a la rígida moral kantiana.

En la vida cotidiana no es tan fácil resolver situaciones complejas, por eso, los individuos se ven obligados a actuar según su conciencia. El mensaje paulino "No hagas nada contra tu conciencia" $(1$ Timoteo, 1,5$)$ respalda las decisiones que se han de tomar para cada caso. Pero, ¿qué sucede cuando se delibera según una conciencia invenciblemente errónea? La conciencia invenciblemente errónea es la incapacidad para conocer los propios deberes. Esta capacidad se ve mermada principalmente por la educación y la fuerza de la costumbre. En esos casos tenemos conflictos no tan fáciles de dar solución por el sentido común y tenemos que enfrentarnos a otras formas de pensar que parten de lógicas diferentes. La conciencia venciblemente errónea tiene un cariz distinto. Como lo dice el enunciado, "venciblemente errónea" es la irresponsabilidad de conocer los propios deberes. La responsabilidad en estos casos se imputa por negligencia o descuido. El profesional que debe actuar de una manera y no lo hace simplemente por descuido de sus verdaderos deberes para cado caso que se le presenta, es un ejemplo típico de conciencia "venciblemente errónea". El abogado que debe consultar el código deontológico para resolver un conflicto y no procede de esta manera, está incurriendo en un caso de negligencia.

De esta manera, observamos cómo en el día a día tenemos que habérnosla con la moral de conciencia y con la ética disciplinaria. Esta última es la base del ius naturalismo, es decir, el derecho natural reclama el respaldo de la moral como consecuencia antropológica. Si aceptamos la concepción aristotélica del fin del hombre como eudemonia (felicidad en la búsqueda del bien común), este camino a la felicidad y a la construcción del bien común

El Principio del derecho prevalente se enuncia así: Cuando el ejercicio de un derecho proporcionado excluye el cumplimiento de un deber, este deber cesa en favor del derecho". Principio también procedente de la moral católica para la resolución de casos de perplejidad. El derecho antecede al deber cuando hay proporción en el derecho que se defiende. Por ejemplo, el derecho de un niño a ser comprendido y recibir educación, frente al "deber" de su maestro de proporcionarle un castigo por inconductas del menor. Cfr. Con respecto a la posibilidad del reconocimiento de los Derechos Humanos como un principio que existió siempre o es simplemente un hijo de nuestro tiempo, véase Williams Bernard (2008) En el principio era la acción. México: Fondo de Cultura Económica, p. 94. 
deben proporcionarnos ideas del fin humano para poder acceder a él. No podemos concebir el fin de la naturaleza humana a ciegas, sin una teleología de base o finalidad que lo sustente.

Nuestra sociedad actual presa de una amoralidad subyacente en todos los campos de la vida, hace que la pregunta por la moralidad se torne aún más urgente. Entendemos por moralidad la sujeción de la sociedad a la ley moral, por inmoralidad, la infracción a la ley moral y la amoralidad, simplemente, la ausencia de moral, es decir, la ausencia de reglas sociales e individuales por las cuales regir la conducta ${ }^{6}$.

Los conceptos antes mencionados explican por sí mismos el porqué de la importancia de la pregunta moral en la cotidianeidad. Aunque no encontremos una respuesta definitiva frente a la cantidad de dilemas morales y casos de perplejidad que se presentan en la vida diaria, sin duda, toda reflexión sobre los mismos se convierte en un desafío para la reflexión sobre la ética en los tiempos que corren.

\section{REFERENCIAS}

Aristóteles (2002). Ética a Nicómaco. México: Centro de Estudios Constitucionales y Políticos.

Kant, Imanuel (1981). Crítica de la razón práctica, México: Ed. Porrua.

Mac Intyre, Alasdair (1987). Tras la virtud, Madrid: Cátedra.

Williams, Bernard (2008). En el principio era la acción, México: Fondo de Cultura Económica.

Fecha de recepción : : 28 de agosto de 2018

Fecha de aceptación : : 26 de octubre 2018

Este concepto no es tan sencillo como pareciera. El individuo humano siempre tiene una moral interna por la cual rige su comportamiento y evalúa sus juicios y toma de decisiones, aunque estando errado. Más arriba lo denominamos conciencia "invenciblemente errónea". 